\title{
The Respiratory Chain of Anaerobically Grown Escherichia coli: Reactions with Nitrite and Oxygen
}

\author{
By RICHARD A. ROTHERY, ALEXANDER M. HOUSTON \\ AND W. JOHN INGLEDEW* \\ Department of Biochemistry and Microbiology, University of St Andrews, \\ St Andrews KY16 9AL, UK
}

(Received 27 April 1987; revised 24 June 1987)

\begin{abstract}
The reactions of nitrite and oxygen with the cytochrome $d$ oxidase of Escherichia coli were studied, following growth of cells on glycerol with fumarate as respiratory oxidant. Optical difference spectroscopy was used to investigate the kinetics of product formation during the reaction of the respiratory chain with nitrite. Two kinetically distinct species were formed in the reaction with nitrite; these had spectral features at $438 \mathrm{~nm}$ and $630 \mathrm{~nm}$. These observations indicate that the cytochrome $d$ does not contribute significantly to absorbance in the Soret region, and that changes elicited by ligand binding in the Soret region are largely attributable to haemoprotein $b$-590. Inhibition of respiratory oxidase activity by nitrite was also investigated. The inhibition was competitive with oxygen $\left(K_{\mathrm{i}} 0.83 \mathrm{mM}, \mathrm{pH} 7\right)$, which allowed analysis of the reaction of the oxidase with oxygen itself. The reaction with oxygen was cooperative with an apparent number of oxygen-binding sites, $n$, of 1.26 at $\mathrm{pH} 7$, increasing to 1.72 at $\mathrm{pH} 6$. We propose a model for the oxidase in which there are two ligand-binding sites.
\end{abstract}

\section{INTRODUCTION}

Escherichia coli, grown anaerobically on the non-fermentable carbon source glycerol, with fumarate as respiratory oxidant, develops a respiratory chain which contains cytochrome $d$ as the major and perhaps sole cytochrome oxidase (Poole \& Ingledew, 1987). Under these conditions cytochrome $d$ is produced in relatively high abundance in the cytoplasmic membrane. This oxidase contains, in addition to cytochrome $d$, cytochrome $b_{558}$ and haemoprotein $b-590$ (Koland et al., 1984), and comprises two subunits, I and II, with $M_{\mathrm{r}}$ values of approximately 70000 and 43000 respectively (Finlayson \& Ingledew, 1985). Both the cytochrome $b_{558}$ and the haemoprotein $b-590$ are protohaem IX centres, whilst the cytochrome $d$ is a chlorin centre (Barrett, 1956; Timkovich et al., 1986). The oxidase contains one or two cytochromes $d$, one haemoprotein $b-590$, and one cytochrome $b_{558}$ centre. Coulometric and CO-binding titrations have been used to suggest the presence of two cytochromes $d$ per mole of the oxidase (Lorence et al., 1986), but the data can be reinterpreted to support the presence of a single cytochrome $d$. The coulometric method used overestimated the total $b$-cytochrome content by $0.3(2 \cdot 3 \pm 0.3)$, and the estimate of the number of cytochromes $d$ present was only $1 \cdot 4 \pm 0 \cdot 3$. The CO-binding data estimated the number of cytochromes $d$ as being $1.6 \pm 0 \cdot 1$; however, as the optical changes elicited in the Soret region by $\mathrm{CO}$ were assumed to be due to the cytochrome $d$ with little contribution from haemoprotein $b-590$, these values may also be overestimations. On the other hand, analyses of the total iron content of the oxidase indicate that the amount of protohaem IX accounts for only half of the total iron present (Kita et al., 1984), which suggests that there may be two $b$-type cytochromes and two cytochromes $d$ present. Cytochrome $b_{558}$ is located in subunit I (Green et al., 1984); this subunit is also responsible for

Abbreviations: ETP, electron transport particles; NED, $N$-(1-naphthyl)ethylenediamine; TMPD, $N, N, N^{\prime}, N^{\prime}-$ tetramethyl-p-phenylenediamine. 
ubiquinol-1 oxidation, whilst subunit II is responsible for TMPD oxidation (Kranz \& Gennis, 1984).

Reaction of the reduced respiratory chain with nitrite in the absence of oxygen causes bleaching of the $630 \mathrm{~nm}$ cytochrome $d$ absorbance (Hubbard et al., 1983; Meyer, 1973); there are also changes elicited in the Soret region which may be due to reaction of nitrite with cytochrome $o$ (Meyer, 1973) or haemoprotein $b-590$. Electron paramagnetic resonance (EPR) spectroscopy shows that paramagnetic species are formed concurrently with the optical changes discussed above (R. A. Rothery \& W. J. Ingledew, unpublished), and that they have EPR signals characteristic of those produced by haem-NO compounds such as cytochrome $a_{3}$ nitroxide (Mascarenhas et al., 1983) and haemoglobin nitroxide (Yonetani et al., 1972). These reactions with nitrite are distinct from the known $E$. coli nitrite reductase pathways, of which there are three (viz. a membrane bound nitrite reductase, a soluble NADPH-dependent enzyme that functions in vivo as a sulphite reductase and a soluble NADH-dependent enzyme; Coleman et al., 1978).

In this paper we have studied the reactions of the respiratory chain with nitrite and oxygen in electron transport particles prepared from cells grown anaerobically on glycerol with fumarate as respiratory oxidant.

\section{METHODS}

Growth of cells. Escherichia coli strain EMG2 (prototroph) was grown at $37^{\circ} \mathrm{C}$ in 20 litre bottles on a mineral salts medium (Cohen \& Rickenberg, 1956) but with the omission of manganese. The medium was supplemented with $0.1 \%(\mathrm{w} / \mathrm{v})$ vitamin-free Casamino acids. The major reductant and carbon source was glycerol $(1 \%, \mathrm{w} / \mathrm{v})$ and the respiratory oxidant was fumarate (100 mM, potassium salt). Cells were harvested in late exponential phase (after $24 \mathrm{~h}$ growth) using an MSE continuous flow rotor running in an MSE High Speed 18 centrifuge at 18000 r.p.m. with a through flow of $250 \mathrm{ml} \mathrm{min}^{-1}$. The cells were washed twice in ice-cold $50 \mathrm{~mm}$-potassium phosphate buffer (pH 7.5) containing $2 \mathrm{mM}$-magnesium sulphate, by resuspension in the buffer followed by recentrifugation at $10000 \mathrm{~g}$ in a Sorvall RC-5B (DuPont) refrigerated centrifuge operating at $4{ }^{\circ} \mathrm{C}$. The pellet was stored at $-30{ }^{\circ} \mathrm{C}$ before preparation of electron transport particles as described below.

Preparation of electron transport particles $(E T P)$. Frozen cells were thawed and suspended in an equal volume of a $20 \mathrm{mM}$-TES/KOH buffer ( $\mathrm{pH} 7.5$ ) containing $5 \mathrm{~mm}-\mathrm{Na}_{2}$ EDTA at $4{ }^{\circ} \mathrm{C}$. Bovine spleen deoxyribonuclease II and lysozyme $\left(2 \mu \mathrm{g} \mathrm{ml}^{-1}\right.$ each) were added to hydrolyse any DNA released during cell breakage and to digest the cell wall peptidoglycan respectively. Cell breakage was achieved by passing the suspension of cells twice through a French press operating between 10 and $15 \mathrm{MPa}$. Cell debris and residual whole cells were removed by centrifuging the lysate at $10000 \mathrm{~g}$ for $15 \mathrm{~min}$. Membrane fragments from the supernatant were pelleted by centrifugation for $90 \mathrm{~min}$ at $125000 \mathrm{~g}$ in a Prepspin 50 ultracentrifuge operating at $4{ }^{\circ} \mathrm{C}$. This pellet was washed by resuspension in the TES-EDTA buffer and recentrifugation at $125000 \mathrm{~g}$ for $90 \mathrm{~min}$. Finally, the pellet was suspended in a minimal volume of the buffer and frozen by pipetting dropwise into liquid nitrogen. ETP were stored under liquid nitrogen until required.

Assays for oxidase and nitrite reductase activity. Anaerobic nitrite reductase activity was measured in ETP and whole cells by a modification of the method of W ray \& Filner (1970). Cells or ETP were incubated anaerobically in $50 \mathrm{~mm}$-potassium phosphate buffer (pH 7) with $20 \mathrm{mM}$-sodium lactate and $2 \mathrm{mM}$-sodium nitrite at $30^{\circ} \mathrm{C}$. Samples were withdrawn into test-tubes containing $3 \mathrm{ml}$ distilled water, $1 \mathrm{ml} 1 \%(\mathrm{w} / \mathrm{v})$ sulphanilamide in $3 \mathrm{M}-\mathrm{HCl}$, and $1 \mathrm{ml} 0.02 \% \mathrm{NED}$. Suspended cells of membrane fragments were centrifuged out and the absorbance was measured at $528 \mathrm{~nm}$. Nitrite reductase activity at pH 7 in whole cells was $1.87 \mathrm{nmol} \mathrm{min}^{-1}(\mathrm{mg} \text { protein })^{-1}$, whereas in ETP it was $0.068 \mathrm{nmol} \mathrm{min}{ }^{-1}(\mathrm{mg} \text { protein) })^{-1}$. This compares with oxidase activities of $153 \mathrm{nmol} \mathrm{min}{ }^{-1}(\mathrm{mg} \text { protein })^{-1}$ with lactate as substrate in ETP.

Rates of oxygen consumption were determined using a Clark type oxygen electrode with a glass incubation vessel (Rank) operating at $30^{\circ} \mathrm{C}$. The Perspex plunger of this electrode was replaced by a ground-glass airtight stopper with a capillary portal through which additions could be made. Lactate $(34 \mathrm{mM})$ was used as reductant. The oxygen electrode was interfaced with a BBC Model B microcomputer (Acorn Computers). Oxygen concentrations were calculated using the data of Chappell (1964). The $\mathrm{pH}$ dependence of nitrite inhibition of oxidase activity was investigated by using a range of buffers between $\mathrm{pH} 5.6$ and $\mathrm{pH} 9.0$. Buffers used were as follows: $50 \mathrm{~mm}$-malonate, $\mathrm{pH} 5.6 ; 50 \mathrm{~mm}-\mathrm{MES}, \mathrm{pH} 6 ; 50 \mathrm{~mm}-\mathrm{TES}, \mathrm{pH}$ 7; and $50 \mathrm{~mm}$-Tricine, $\mathrm{pH} 8$ ( $\mathrm{pH}$ values adjusted using $\mathrm{KOH}$ or $\mathrm{HCl}$ ). All buffers contained $2 \mathrm{mM}$-magnesium sulphate. Mixtures were used at intermediate $\mathrm{pH}$ with a total buffer concentration of $50 \mathrm{mM}$.

Protein was determined by the Lowry method modified by the inclusion of $1 \%(w / v)$ SDS in the incubation mixture to solubilize membrane-bound protein. 
Data analysis. Where appropriate, data collected from the oxygen electrode were transferred to the University's mainframe computer for analysis. Rates of oxygen consumption were determined using a noise-averaging differentiating algorithm. For each concentration of nitrite used, the $V_{\max }$ of the oxidase reaction was determined by measurement of the gradient of a plot of $s / v$ versus $s$ (the Hanes plot). Other parameters were determined by analysis of a plot of $v$ versus $v / s$ (the Eadie-Hofstee plot). In cases where positive cooperativity is observed, the value of $v / s$ reaches a maximum, and the coordinates of this maximum can be used to determine the $K_{\mathrm{m}}$ for substrate binding and the apparent number of substrate-binding sites, $n$ (Segel, 1975).

Spectroscopy. Optical difference spectra were obtained using a split beam spectrophotometer constructed in the workshop of the Department of Biochemistry and Microbiology at the University of St Andrews. Cytochrome $d$ concentrations were determined using the differential extinction coefficient quoted by Reid \& Ingledew (1980) as $5.3 \mathrm{~mm}^{-1} \mathrm{~cm}^{-1}$ for the wavelength pair $630-610 \mathrm{~nm}$. Lactate was used as reductant (10 mM) and difference spectra were recorded anaerobically of lactate reduced + nitrite minus lactate reduced. The kinetics of the reaction of ETP with nitrite were investigated by following the reaction at a fixed wavelength in the spectrophotometer. All optical spectra were recorded at $30^{\circ} \mathrm{C}$.

Chemicals. Tricine, MES, TES, malonic acid, lysozyme and deoxyribonuclease II were obtained from Sigma. Sulphanilamide and NED were obtained from BDH. Sodium nitrite was obtained from Fisons. Other chemicals were obtained from $\mathrm{BDH}$ or Sigma.

\section{RESULTS}

\section{Changes in the optical absorption spectra of cytochromes elicited by nitrite}

A reduced minus oxidized difference spectrum of ETP is shown in Fig. 1 (top). Noticeable in this spectrum are the broad absorption differences in the Soret region (around $435 \mathrm{~nm}$ ) and the prominent peaks at $560 \mathrm{~nm}$ (cytochrome $b$, alpha band) and $630 \mathrm{~nm}$ (cytochrome $d$, alpha band). The trough at $650 \mathrm{~nm}$ arises because the oxidized form of cytochrome $d$ has an absorbance maximum in this region, whilst the reduced form has an absorbance maximum around $630 \mathrm{~nm}$. In addition to the $b$ and $d$ type cytochromes, a small peak at approximately $590 \mathrm{~nm}$ can be distinguished. This absorption is attributed to haemoprotein $b-590$ (Poole et al., 1986). The effect of nitrite on the cytochrome spectra can be seen in Fig. $1(a-d)$. Trace BL (baseline) is a reduced minus reduced spectrum of the membrane preparation used, and traces $(a)-(d)$ are reduced + nitrite minus reduced spectra taken at successive times after addition of nitrite $(15 \mathrm{~s}$, $14 \mathrm{~min}, 21 \mathrm{~min}$ and $51 \mathrm{~min}$, respectively). It can be seen that a reaction resulting in an apparent bleaching of the cytochrome $d$ alpha band (inverse of the reduced minus oxidized spectrum) goes to completion within the time-span taken to produce spectrum $(a)$. This rapid reaction is not accompanied by any other detectable change of comparable rate. A relatively slow absorption change in the Soret region (maximum at $438 \mathrm{~nm}$ ) can be discerned in the spectra of Fig. 1; this change is quite large compared with the control reduced minus oxidized spectrum (top). A parallel change is barely discernable at $590 \mathrm{~nm}$, and this link is strengthened by a kinetic analysis of this respiratory chain from which it has been suggested that the $438 \mathrm{~nm}$ component is part of the spectrum of haemoprotein $b-590$ (D. S. Wariabharaj \& W. J. Ingledew, unpublished). The broad absorbance change at approximately $560 \mathrm{~nm}$ can be attributed to the beta band of haemoprotein $b-590$ (Poole et al., 1986).

\section{Kinetics of the nitrite-induced spectral change at $630 \mathrm{~nm}$}

The time-course of the nitrite-induced change in alpha band absorption was studied in greater detail by monitoring absorption at a fixed wavelength of $630 \mathrm{~nm}$. The rate of reaction is dependent on both the concentration of nitrite and the $\mathrm{pH}$. Progress curves of the $630 \mathrm{~nm}$ change at different nitrite concentrations are shown in Fig. 2(a). The rate of reaction is more rapid at lower $\mathrm{pH}$ values (Fig. $3 a$ ), but the extent of the reaction is unaltered. The relationship between the velocity of the reaction and proton concentration at two different concentrations of unreacted cytochrome $d$ is shown in Fig. 3(a). Above $\mathrm{pH} 8$ the reaction is first-order with respect to protons, whilst it is less than first-order below this pH. Fig. 3(b) shows the relationship between the velocity of the reaction and the concentration of unreacted cytochrome $d$ for a range of concentrations of nitrite. The order of the reaction with respect to cytochrome $d$ decreases with increasing nitrite concentration. At low nitrite concentrations the reaction tends towards 


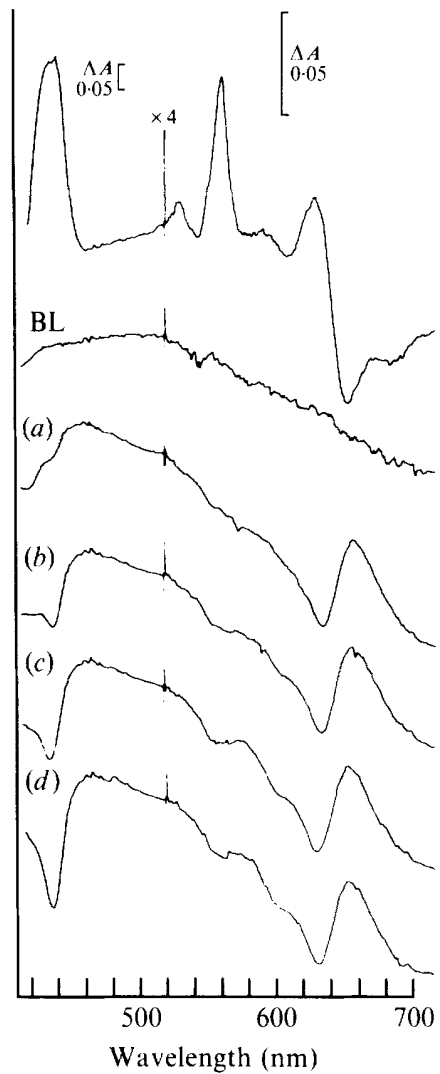

Fig. 1. Optical difference spectra taken during the reaction of membranes with nitrite. Spectra of suspensions of ETP ( $7 \mathrm{mg}$ protein $\mathrm{ml}^{-1}$ ) showing reduced minus oxidized (top), baseline BL, and reduced + nitrite minus reduced spectra taken at different times after addition of $10 \mathrm{mM}$-nitrite to ETP reduced with $10 \mathrm{~mm}$-lactate at $\mathrm{pH} 7:(a) 15 \mathrm{~s}$; (b) $14 \mathrm{~min}$; (c) $21 \mathrm{~min}$; (d) $51 \mathrm{~min}$. The reaction with nitrite $(a-d)$ causes absorbance changes in the $438 \mathrm{~nm}, 560 \mathrm{~nm}, 590 \mathrm{~nm}$, and $630 \mathrm{~nm}$ bands of the reduced minus oxidized spectrum (top). The change at $630 \mathrm{~nm}$ is essentially complete within the time taken to record the first spectrum $(a)$.

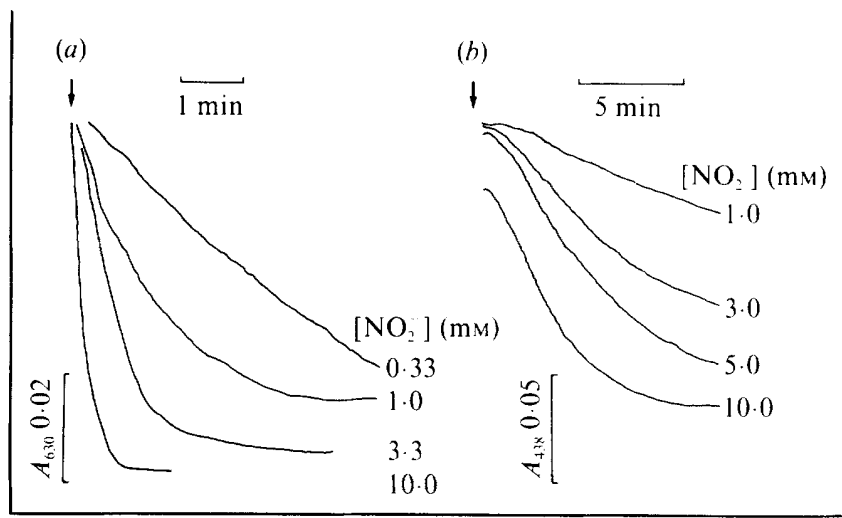

Fig. 2. Progress curves of the optical changes induced by nitrite. Nitrite was added to ETP (7 mg protein $\mathrm{ml}^{-1}$ ) reduced with $10 \mathrm{~mm}$-lactate. The curves were recorded with lactate-reduced ETP in the reference cuvette. (a) $630 \mathrm{~nm}$ reaction; (b) $438 \mathrm{~nm}$ reaction. 

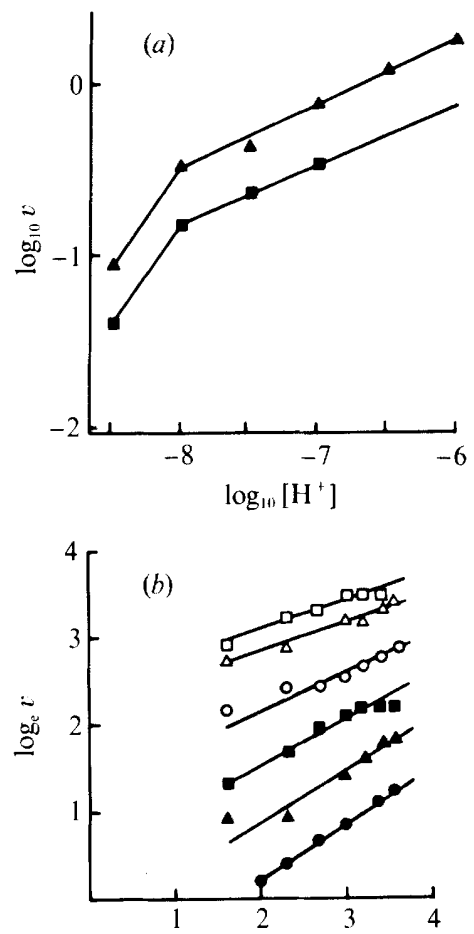

$\log _{\mathrm{e}}[$ Cytochrome $d]$

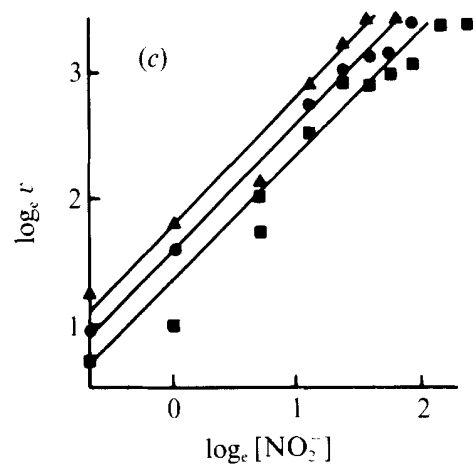

Fig. 3

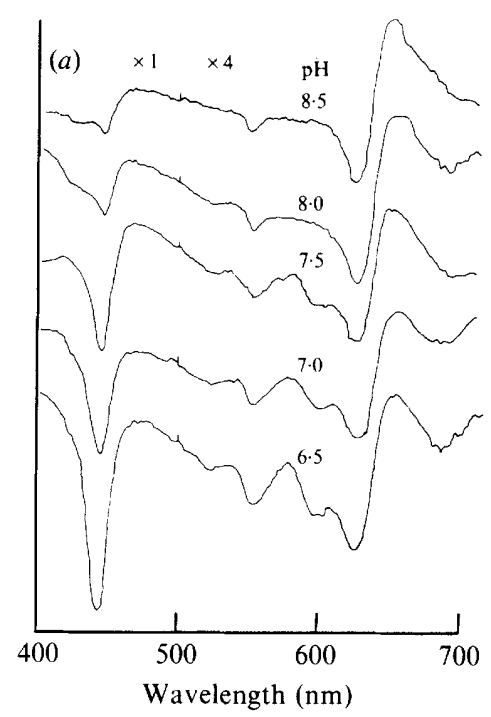

(b)

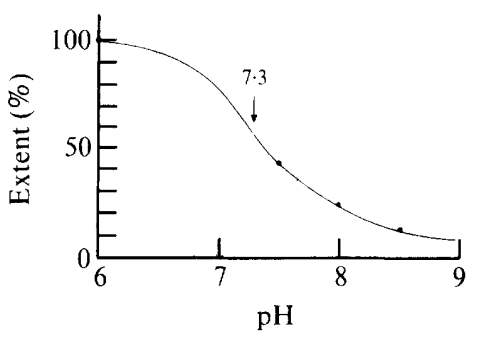

Fig. 4

Fig. 3. Orders of the $630 \mathrm{~nm}$ reaction with respect to nitrite, protons and cytochrome $d$. Data were collected by analysis of progress curves recorded as in Fig. 2(a). (a) Velocity of the $630 \mathrm{~nm}$ reaction versus concentration of protons: $\square, \log$ rate of reaction with $0.007 A_{630}$ cytochrome $d(1.32 \mu \mathrm{M})$ remaining; $\Delta, \log$ rate of reaction with $0.02 A_{630}(3.77 \mu \mathrm{M})$ cytochrome $d$ remaining. Reactions were initiated by adding $1 \mathrm{mM}$-nitrite to a suspension of ETP $\left(7 \mathrm{mg}\right.$ protein $\left.\mathrm{ml}^{-1}\right)$ reduced with $10 \mathrm{mM}$ lactate. (b) Velocity of the reaction versus concentration of cytochrome $d$. Reaction order was determined at $\mathrm{pH} 8$ with different concentrations of nitrite: $\mathbf{O}, 0.5 \mathrm{~mm} ; \boldsymbol{\Lambda}, 1 \mathrm{mM} ; \mathbf{\square}, 2 \mathrm{mM} ; 0,3 \mathrm{~mm}$; $\triangle, 4 \mathrm{mM} ; \square, 10 \mathrm{~mm}$. Protein concentration $7 \mathrm{mg} \mathrm{ml}^{-1}$. (c) Velocity of the reaction versus the concentration of nitrite. $\square, 0.005 A_{630}(0.94 \mu \mathrm{M})$ cytochrome $d$ remaining; $\boldsymbol{\Delta}, 0.035 A_{630}(6.60 \mu \mathrm{M})$ cytochrome $d$ remaining;, $0.025 A_{630}(4.72 \mu \mathrm{M})$ cytochrome $d$ remaining. Protein concentration $8.9 \mathrm{mg} \mathrm{ml}^{-1} ; \mathrm{pH} 7 \cdot 0$.

Fig. 4. Effect of $\mathrm{pH}$ on the optical changes. (a) Spectra after completion of reaction at different $\mathrm{pH}$ values. Reduced + nitrite minus reduced difference spectra are illustrated between $\mathrm{pH} 6.5$ and 8 . ETP reduced with $10 \mathrm{~mm}$-lactate were reacted with $10 \mathrm{~mm}$-nitrite. Protein concentration $7.0 \mathrm{mg} \mathrm{ml}^{-1}$. (b) Extent of the $438 \mathrm{~nm}$ reaction versus $\mathrm{pH}$. 
first-order, whilst with increasing nitrite concentration it approaches an order of $0 \cdot 25$. Fig. $3(c)$ shows the relationship between the concentration of nitrite and the rate of reaction. The reaction is first-order with respect to nitrite and there is no change in order with increasing nitrite concentration.

\section{Kinetics of the nitrite-induced spectral change in the Soret region}

The reaction of nitrite with the E. coli respiratory chain was monitored in the Soret region at a fixed wavelength of $438 \mathrm{~nm}$. This reaction is considerably slower than that considered in the previous section. Its initial rate under the conditions used for Fig. 2(b) at $10 \mathrm{~mm}$-nitrite was only 0.02 absorbance units $\min ^{-1}$, whilst the rate of the $630 \mathrm{~nm}$ change was 0.20 absorbance units $\min ^{-1}$ (both rates measured at $\mathrm{pH} 7$ with a protein concentration of $7 \mathrm{mg} \mathrm{ml}^{-1}$ ). The $\mathrm{pH}$ dependence of the reaction rate was similar to that observed at $630 \mathrm{~nm}$ although in this case the extent of the reaction was also pH-dependent. Fig. $4(a)$ shows spectra taken after completion of the reaction of membranes with nitrite and Fig. $4(b)$ shows the effect of the $\mathrm{pH}$ on the extent of the $438 \mathrm{~nm}$ change. A pH-dependent equilibrium is suggested with a $\mathrm{p} K_{\mathrm{a}}$ of $7 \cdot 3$. The kinetics of the $438 \mathrm{~nm}$ reaction are therefore more complex than those of the $630 \mathrm{~nm}$ change.

\section{Effect of nitrite on oxygen consumption in ETP}

In the absence of nitrite, there is a slight initial acceleration in the rate of oxygen consumption by $E$. coli ETP with decreasing oxygen concentration. The rate of the oxidase reaction increases by $7 \%$ when the oxygen concentration decreases from $0.18 \mathrm{~mm}$ to $0.06 \mathrm{mM}$ at $\mathrm{pH} 7$. This effect is not a function of the oxidase reaction, since it occurs at oxygen tensions where the lactate dehydrogenase activity is rate-limiting. Nitrite inhibits oxygen consumption by ETP and its use allows analysis of the oxidase reaction itself. The oxidase reaction has a very low $K_{\mathrm{m}}$ for oxygen $(0.23 \mu \mathrm{M}$, Kita et al., 1984) and this reaction can be more easily studied by artificially increasing its $K_{\mathrm{m}}$ using a competitive inhibitor. The nitrite-inhibited enzyme exhibits cooperative steadystate kinetics (Fig. $5 a, b)$ and there is an increase in the apparent number of sites $(n)$ with decreasing $\mathrm{pH}$, from 1.26 at $\mathrm{pH} 7$ to 1.72 at $\mathrm{pH} 6$ (Fig. 6). This increase is linear over the $\mathrm{pH}$ range studied with a gradient of -0.46 sites per $\mathrm{pH}$ unit.

\section{pH dependence of nitrite inhibition}

The oxidase reaction in ETP with lactate as reductant is $\mathrm{pH}$-dependent with an optimum at $\mathrm{pH} 6.8$ in the presence of $0.098 \mathrm{~mm}$-oxygen. This compares with a reported optimum of $\mathrm{pH} 7.5$ for the purified cytochrome $d$ complex (Lorence et al., 1984). Nitrite (16 mM) alters the apparent $\mathrm{pH}$ optimum of the oxidase reaction to $\mathrm{pH} 7.8$ and becomes a more potent inhibitor of the oxidase reaction with decreasing $\mathrm{pH}$ from $\mathrm{pH} 7 \cdot 8$. The $K_{\mathrm{i}}$ values for nitrite were calculated assuming that the $K_{\mathrm{m}}$ for the oxidase reaction was $0 \cdot 23 \mu \mathrm{M}$ (Kita et al., 1984). The $\mathrm{p} K_{\mathrm{i}}\left(-\log _{10}\right.$ $K_{\mathrm{i}}$ ) for nitrite increases from 3.1 at $\mathrm{pH} 7$ to 4.7 at pH 6 (Fig. 6); this variation is linear with respect to $\mathrm{pH}$ with a gradient of -1.6 . A small nitrite-induced activation of the reaction rate is observed at low oxygen concentrations above $\mathrm{pH} 7.8$ (data not shown). This is not an ionic effect, but the reasons for it are unknown.

\section{DISCUSSION}

The reactions of anaerobic $E$. coli membranes with nitrite show complex kinetics which are both concentration- and $\mathrm{pH}$-dependent. Two optically resolvable species can be detected: a nitroxide adduct to the cytochrome $d$ which partially bleaches the $630 \mathrm{~nm}$ absorbance of reduced ETP, and a nitroxide adduct to the haemoprotein $b-590$ which bleaches the $438 \mathrm{~nm}$ absorbance of reduced ETP. Parallel EPR experiments also indicate that two species are formed when ETP are reacted anaerobically with nitrite (R. A. Rothery \& W. J. Ingledew, unpublished). The cytochrome $d$ species appears through a range of $\mathrm{pH}$ values between 6 and $8 \cdot 5$, whilst the haemoprotein $b-590$ species appears only at lower $\mathrm{pH}$ values.

Analysis of the kinetics of the formation of the $630 \mathrm{~nm}$ species reveals that the reaction shows constant order only with respect to nitrite concentration (first-order). The order of the reaction 

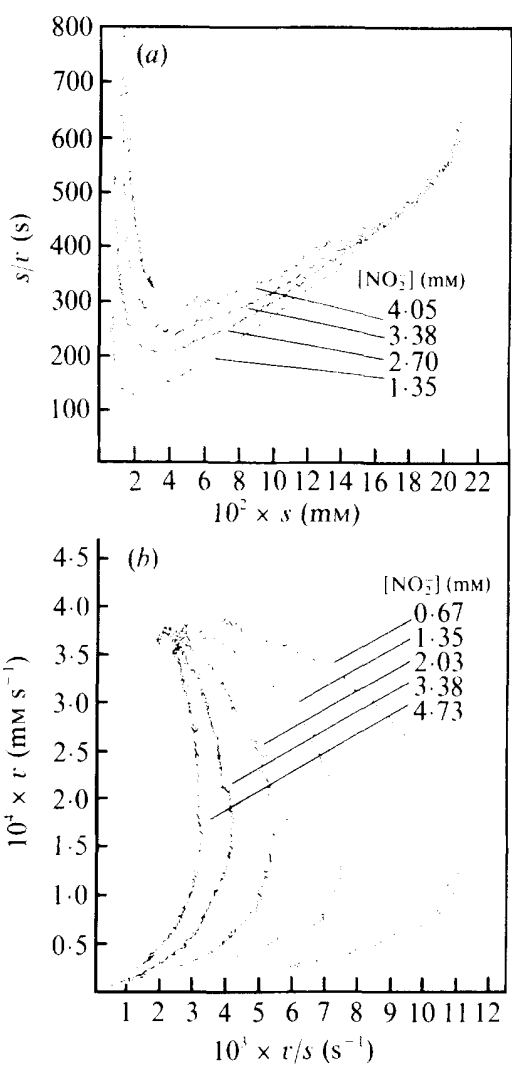

Fig. 5

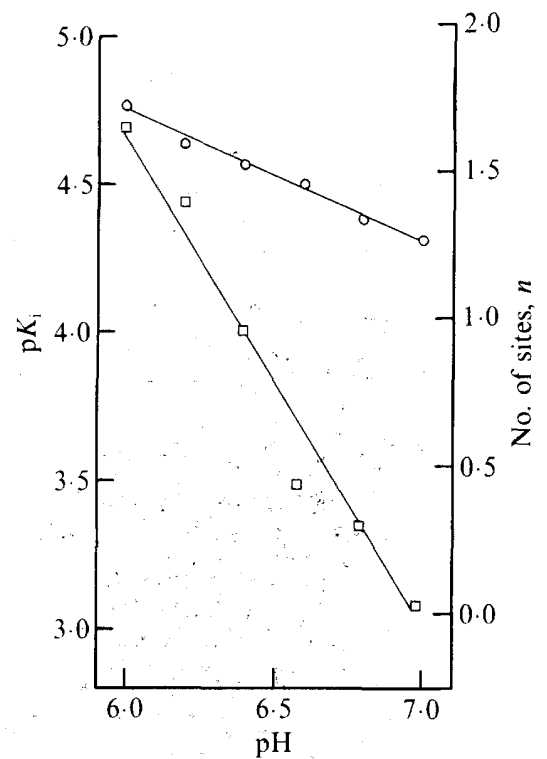

Fig. 6

Fig. 5. Eadie-Hofstee $(a)$ and Hanes $(b)$ plots for the nitrite-inhibited oxidase reaction. Data were obtained from differentiated oxygen electrode progress curves at $\mathrm{pH} 6.0$ using 34 mM-lactate as reductant and with a protein concentration of $0.27 \mathrm{mg} \mathrm{ml}^{-1}$.

Fig. 6. Effect of $\mathrm{pH}$ on the $\mathrm{p} K_{\mathrm{i}}$ of nitrite $(\square)$ and the apparent number of sites, $n(O)$. The rate of change of $\mathrm{p} K_{\mathrm{i}}$ is -1.6 , whilst that of the apparent number of sites was -0.46 sites per $\mathrm{pH}$ unit.

with respect to cytochrome $d$ varies between 0.25 at high nitrite concentrations and approximately one at low nitrite concentrations. Therefore, only a single cytochrome $d$ is involved kinetically in the formation of the $630 \mathrm{~nm}$ species. The rate of formation of the $630 \mathrm{~nm}$ species is $\mathrm{pH}$-dependent, and this is consistent with nitrous acid being the reactive species. However, this does not explain the increase in reaction order above pH 8 and this may be due to the ionization of a functional group with a $\mathrm{p} K_{\mathrm{a}}$ approaching 8 . The formation of the nitroxide adduct to the cytochrome $d$ is much as expected, and appears to be monophasic with a reaction of one cytochrome $d$ with one nitrous acid.

The reduced minus oxidized spectrum of the cytochrome $d$ oxidase has an absorption in the Soret region at $438 \mathrm{~nm}$. This is due to the presence of the $b$ type cytochromes $b-590$ and $b_{558}$ (Poole et al., 1981). Since cytochrome $b_{558}$ does not react directly with oxygen, the bleaching of the Soret band at $438 \mathrm{~nm}$ by nitrite is most likely to be due to a reaction of haemoprotein $b-590$ with nitrite. This has been confirmed by analysis of the pre-steady-state kinetics of the reaction of the electron transport chain containing the cytochrome $d$ oxidase with oxygen (D. S. Wariabharaj \& W. J. Ingledew, unpublished) and by the parallel optical change at $590 \mathrm{~nm}$. However, the optical changes associated with the $b-590$ are also consistent with oxidation of this species rather than formation of a nitroxide adduct. Both the extent (Fig. $4 b$ ) and the rate of this reaction are $\mathrm{pH}$-dependent. The $\mathrm{pH}$ profile of its extent indicates a $\mathrm{pH}$-dependent equilibrium with a $\mathrm{p} K_{\mathrm{a}}$ of $7 \cdot 3$. The stability of the haemoprotein $b-590$ species responsible for the $438 \mathrm{~nm}$ 
optical change is therefore $\mathrm{pH}$-dependent. An explanation for this is that the reaction between the $b-590$ and nitrite is linked via a $\mathrm{pH}$-dependent equilibrium between the two centres; the formation of the $438 \mathrm{~nm}$ species proceeds via formation of the $630 \mathrm{~nm}$ species and the nitroxide ligand can only be transferred at low $\mathrm{pH}$ values. This is consistent with a model for the cytochrome $d$ oxidase complex in which the two ligand-binding sites are in close proximity.

The cooperative steady-state kinetics of the oxidase reaction suggest cooperativity between two oxygen-binding centres. The decrease in the apparent number of substrate-binding sites with increasing $\mathrm{pH}$ indicates that the affinity of one of these sites has a pronounced $\mathrm{pH}$ dependence; the optical data suggest that the ligand-binding behaviour of haemoprotein $b-590$ is responsible for this effect. The steady-state kinetics of the oxidase reaction catalysed by the cytochrome $c d_{1}$ complex of Pseudomonas aeruginosa show negative cooperativity (Ingledew \& Saraste, 1979). This enzyme contains two cytochromes $d_{1}$ and two cytochromes $c$ with the former acting as binding sites for oxygen. The negative cooperativity is therefore between the two identical binding sites for oxygen. We suggest that the situation in the cytochrome $d$ complex of $E$. coli is different, with two types of oxygen-binding centres, cytochrome $d$ and haemoprotein $b-590$, and positive cooperativity.

Inhibition of oxidase activity by nitrite is $\mathrm{pH}$-dependent, nitrite becoming a more potent inhibitor with decreasing $\mathrm{pH}$ from about $\mathrm{pH} 7 \cdot 4$. The $\mathrm{p} K_{\mathrm{i}}$ for nitrite as an inhibitor increases with decreasing $\mathrm{pH}$ and is consistent with nitrous acid being the inhibitory species. The slope of Fig. 6 is approximately -1.6 and is 0.6 more negative than could be explained purely by the increase in nitrous acid concentration. These results suggest that inhibitor binding is accompanied by binding of a single proton (see Dixon, 1953).

The formation of the optically observed species is distinct from the inhibition of the oxidase activity by nitrite, as they are not detectable in the presence of oxygen. Nitrous acid has been identified as the species responsible for the formation of the $630 \mathrm{~nm}$ optical species and for the inhibition of the oxidase reaction. Both the optical and polarographic data presented here point to a model for the oxidase which has two binding sites for oxygen which are in close proximity. It is uncertain whether these two binding sites are cytochromes $d$ or whether one of them is cytochrome $d$ and the other haemoprotein $b-590$, although the evidence presented here favours oxygen binding to a single cytochrome $d$ site and to the haemoprotein $b$-590. The oxidase reaction would only be cooperative if the reaction cycle involves a mechanism which proceeds more rapidly when both adjacent centres are bound to oxygen. For example, the reaction cycle may involve disproportionation between two bound peroxides leading to a residual bound oxygen and two molecules of water. There is evidence that the aerobically oxidized enzyme has an oxygen bound to the cytochrome $d$ (Hata et al., 1985; Koland et al., 1984); this would be consistent with cooperativity being observed at oxygen tensions where the oxygen begins to become dissociated from the cytochrome $d$.

This work was supported by a research grant (no. GR/D/0853) from the Science and Engineering Research Council to W. J. Ingledew and a studentship from the same source to R. A. Rothery.

\section{REFERENCES}

BARRETT, J. (1956). The prosthetic group of cytochrome $\mathrm{a}_{2}$. Biochemical Journal 64, 626-639.

Chappell, J. B. (1964). The oxidation of citrate, isocitrate, and cis-aconitate by isolated mitochondria. Biochemical Journal 90, 225-237.

Cohen, G. N. \& RickenberG, H. W. (1956). Concentration specifique reversible des amino acides chez Escherichia coli. Annales de l'Institut Pasteur 91, 693-720.

Coleman, K. J., Cornish-Bowden, A. \& Cole, J. A. (1978). Purification and properties of nitrite reductase from Escherichia coli K12. Biochemical Journal 175, 483-493.
Dixon, M. (1953). The effect of $\mathrm{pH}$ on the affinities of enzymes for substrates and inhibitors. Biochemical Journal 55, 161-170.

Finlayson, S. D. \& Ingledew, W. J. (1985). Cytochrome bd of Escherichia coli: its isolation and study by electron paramagnetic resonance spectroscopy. Biochemical Society Transactions 13, 632-633.

Green, G. N., Kranz, R. G., Lorence, R. M. \& GENNIS, R. B. (1984). Identification of subunit I as the cytochrome $b_{558}$ component of the cytochrome $d$ terminal oxidase complex of Escherichia coli. Journal of Biological Chemistry 259, 7994-7997.

Hata, A., Kirino, Y., MatsuUra, K., Itoh, S., 
Hiyama, T., Konishi, K., Kita, K. \& AnRakU, Y. (1985). Assignment of ESR signals of Escherichia coli terminal oxidase complexes. Biochimica et biophysica acta 810, 62-72.

Hubbard, J. A. M., Hughes, M. N. \& Poole, R. K. (1983). Nitrite, but not silver, ions induce spectral changes in Escherichia coli cytochrome d. FEBS Letters 164, 241-243.

InGLedew, W. J. \& SARASTE, M. (1979). The reaction of cytochrome $c d_{1}$ with oxygen and peroxides. Biochemical Society Transactions 7, 166-168.

KITA, K., KoniSHI, K. \& ANRAKU, Y. (1984). Terminal oxidases of Escherichia coli aerobic respiratory chain: purification and properties of cytochrome $b_{558}-d$ complex from cells grown with limited oxygen and evidence of branched electron carrying systems. Journal of Biological Chemistry 259, 33753381 .

Koland, J. G., Miller, M. J. \& Gennis, R. B. (1984). Potentiometric analysis of the purified cytochrome $d$ terminal oxidase complex from Escherichia coli. Biochemistry 23, 1051-1056.

Kranz, R. G. \& Gennis, R. B. (1984). Characterisation of the cytochrome $d$ terminal oxidase complex of Escherichia coli using polyclonal and monoclonal antibodies. Journal of Biological Chemistry 259, 7998-8003.

LoRence, R. M., Miller, M. J., Borochov, A., Faiman-Weinberg, R. \& Gennis, R. B. (1984). Effects of $\mathrm{pH}$ and detergent on the kinetic and electrochemical properties of the purified cytochrome $d$ terminal oxidase complex of Escherichia coli. Biochimica et biophysica acta 790, 148-153.

LORENCE, R. M., Koland, J. G. \& GenNis, R. B. (1986). Coulometric and spectroscopic analysis of the purified cytochrome $d$ complex of Escherichia coli: evidence for the identification of "cytochrome $a_{1}{ }^{\prime}$ as cytochrome $b_{558}$. Biochemistry 25, 2314-2321.

Mascarenhas, R., Wei, Y., Scholes, C. P. \& King, T. E. (1983). Interaction in cytochrome $c$ oxidase between cytochrome $a_{3}$ ligated with nitric oxide and cytochrome a. Journal of Biological Chemistry 258, 5348-5351.
MEYER, D. J. (1973). Interaction of cytochrome oxidases $a a_{3}$ and $d$ with nitrite. Nature New Biology 245, 276-277.

PoOle, R. K. \& INGledew, W. J. (1987). Pathways of electrons to oxygen. In Escherichia coli and Salmonella typhimurium Cellular and Molecular Biology. Edited by J. Ingraham, K. B. Low, B. Magasanik, M. Schaetcher, H. E. Umbarger \& F. C. Neidhart. Washington, DC: American Society for Microbiology (in the Press).

Poole, R. K., Scott, R. 1. \& Chance, B. (1981). The light-reversible binding of carbon monoxide to cytochrome $a_{1}$ in Escherichia coli K12. Journal of General Microbiology 125, 431-438.

Poole, R. K., Baines, B. S. \& Appleby, C. A. (1986). Haemoprotein $b-590$ (Escherichia coli), a reducible catalase and peroxidase: evidence for its close relationship to hydroperoxidase I and a "cytochrome $a_{1} b^{\prime}$ preparation. Journal of General Microbiology 132, $1525-1539$.

ReID, G. A. \& Ingledew, W. J. (1890). The purification of a respiratory oxidase complex from Escherichia coli. FEBS Letters 109, 1-4.

SEGEL, I. H. (1975). Enzyme Kinetics: Behavior and Analysis of Steady State Enzyme Systems, p. 353. New York: Wiley Interscience.

TImkovich, R., CoRK, M. S., GenNis, R. B. \& Johnson, P. Y. (1986). Proposed structure of haem $d$, a prosthetic group of bacterial terminal oxidases. Journal of the American Chemical Society 107, 60696075.

WraY, J. L. \& Filner, J. L. (1970). Structural and functional relationships of enzyme activities induced by nitrate in barley. Biochemical Journal 119, 715725.

Yonetani, T., Yamamoto, H., Erman, J. E., Leigh, J. S. \& REED, G. H. (1972). Electromagnetic properties of hemoproteins: optical and electron paramagnetic resonance characteristics of nitric oxide derivatives of metalloporphyrin-apohemoprotein complexes. Journal of Biological Chemistry 247, 2447-2455. 